\title{
Unfolding of HIV Epidemic and Spectrum of AIDS in North India
}

\author{
Shobha Sehgal \\ Department of Immunopathology, Post Graduate Institute of Medical Education and \\ Research Chandigarh, India \\ Email: Shsehgal@icloud.com
}

Received 10 October 2013; revised 10 November 2013; accepted 17 November 2013

Copyright (C) 2014 by author and Scientific Research Publishing Inc.

This work is licensed under the Creative Commons Attribution International License (CC BY). http://creativecommons.org/licenses/by/4.0/

(c) (i) Open Access

\section{Abstract}

The review traces the unfolding of HIV epidemic in North India. The first few cases were reported in 1989 in Indians returning from African countries like Uganda, Zambia and a trickle from USA. Subsequently the cases started pouring from coastal areas of Mumbai, Chennai and finally the virus spread all over through rail and road. In the North eastern region or the golden triangle, IV drug users formed a major group. Using a simple peptide ELISA, it was documented that the virus belonged to the NOF strain. This was much before clades were identified using molecular analysis. It appears that the HIV virus followed the drug (mandrax) route between Mumbai and South Africa. An alarming rise was observed among truck drivers fuelling HIV in Punjab villages who indulged in promiscuous behavior in road side making shift brothels near eating kiosks. Special customs in the state also flared the spread. During the early epidemic a very high prevalence was shown in blood transfused individuals $(12.5 \%)$ which dropped to $2 \%-3 \%$ after aggressive measures taken by the NACO. While HIV positivity rates plateaued in some states by 2004, infection in Punjab continued to rise even after 2005. Kaposi sarcoma is almost unknown in Indian patients while TB and candida formed major co-infections. In one study, subtype V3 - V5 region chimeras of Indian clade C and clade B replicated freely in peripheral blood mononuclear cells (PBMC) and macrophages and showed higher HIV replication. Opt-out screening was started in an emergency setting in a tertiary care hospital. The positivity rate was 20/per thousand. Thus a large number of patients would have been missed if opt-out screening was not resorted to.

\section{Keywords}

HIV/AIDS; Unfolding in North India; Punjab; Link to South Africa 


\section{Introduction}

At the beginning of 1986, despite that over 20,000 reported AIDS cases worldwide [1], India had no reported cases of HIV or AIDS [2]. It was envisaged that this would not be the case for long and concerns were raised about how India would cope once HIV and AIDS cases started to emerge. Later in the year, when India's first cases of HIV were diagnosed among sex workers in Chennai, Tamil Nad [3] amidst denial, it was never predicted that the country would witness a full blown epidemic in this region. It was noted that contact with foreign visitors had played a significant role in initial infections among sex workers.

At the PGIMER Chandigarh, the first HIV positive case from Punjab was documented in May 1987 in a patient returning from Uganda with genital herpes, molluscumcontagiosum, oral and esophageal candidiasis (Figure 1); the latter being mistaken for cancer of the esophagus [4].

Subsequently Nehru Hospital witnessed stray cases from Congo, Zambia, USA and students from African countries seeking admission to Indian universities and truckers (Figure 2). HIV infected foreign students in India posed a new problem in 1989-90. Out of a total of 2749 foreign students who came to Chandigarh, India between June 1989 and October 1990, 35 were confirmed positive [5] but this influx was terminated within a year as all those who were positive were denied admission. At the Post Graduate Institute of Medial Education and Research (PGIMER), Chandigarh, a total of 58,890 subjects were screened for HIV infection between June1987 to December 1992.

Out of these, 42,276 were blood donors and 9 were positive for HIV by ELISA. Out of the remaining high risk subjects, 141 of 13,365 were confirmed to be HIV positive with a cumulative positively rate of 10.5 per thousand, 47/141 had full blown disease [6] and 50\% died within 6 months of diagnosis. Thirty seven i.e., 24.6 per cent had acquired infection through unscreened blood/products/hemodialysis.

Thus Punjab showed a steady rise of HIV infection during 1987 to 2005 (Figure 3) and the incidence of blood borne infection was very high during this period. A special custom of adjusting the widow in the family fueled further spread (Figures 4(a) and (b)).

\section{Time Trends of HIV Epidemic in Punjab over a Decade}

Trends were further evaluated at our center using a study spanning a decade [7] which showed that the incidence

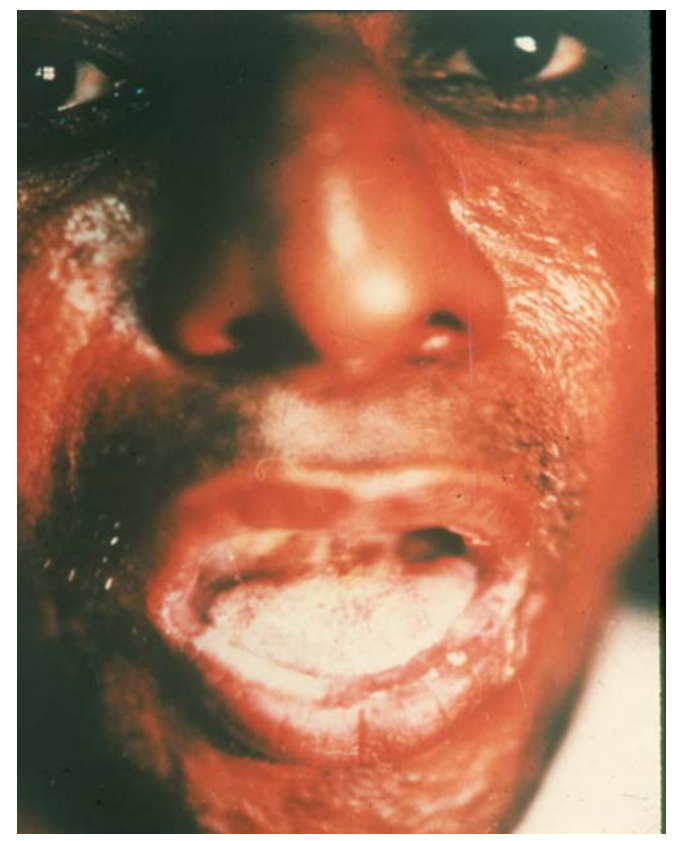

Figure 1. The first case of AIDS returning from Uganda with dementia, extensive esophageal and oral candidiasis, genital Herpes and molluscumcontageousum. 


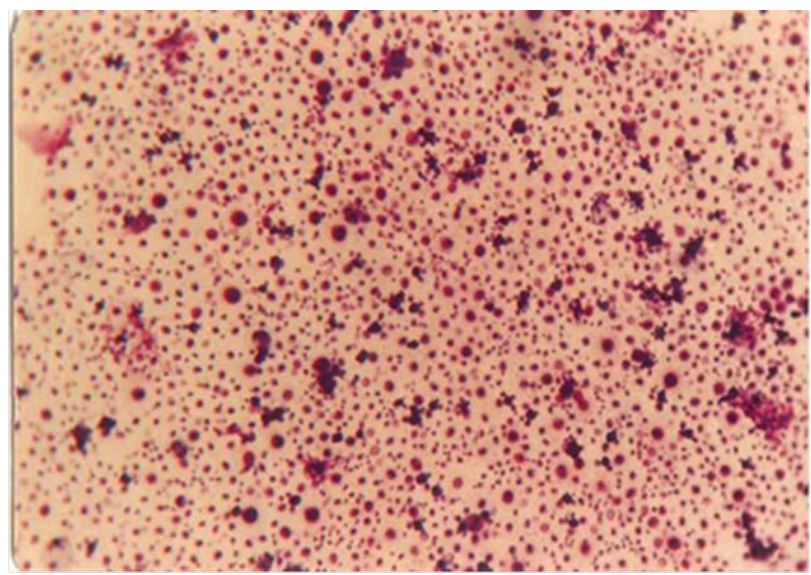

Figure 2. Geimsa stain of cytospin preparation of CSF of the first trucker. Field appears to be a pure culture of cryptococci.

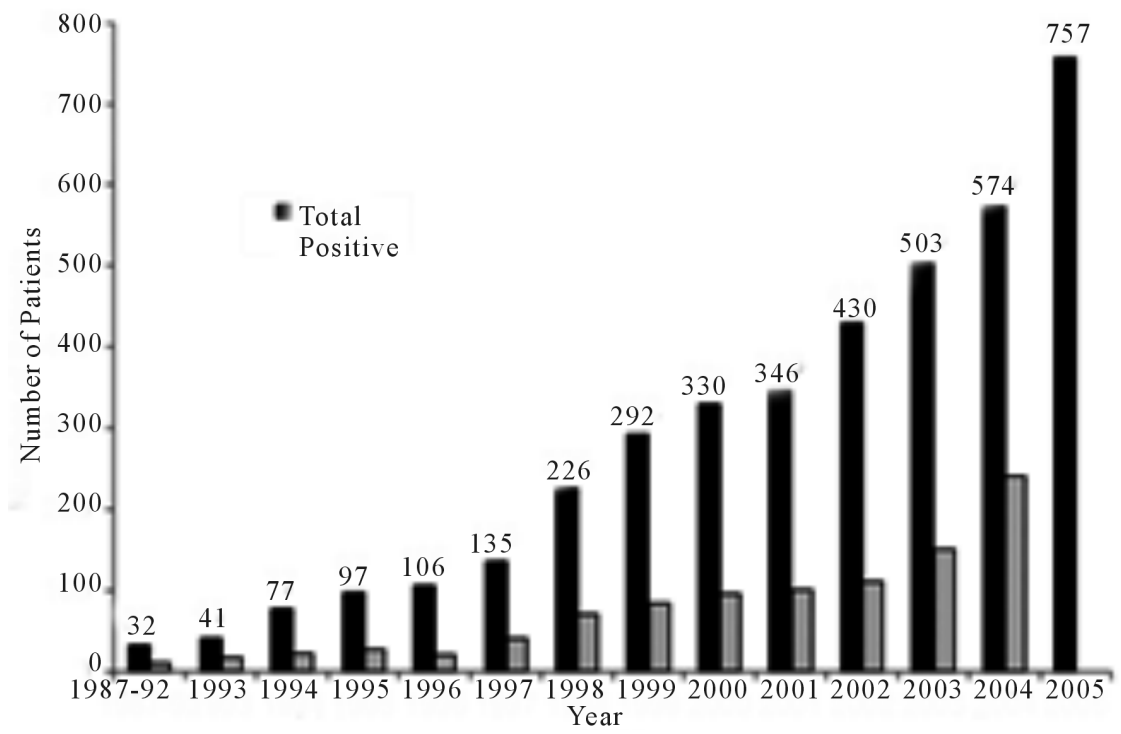

Figure 3. Time trends of AIDS in North India.

in high-risk groups increased from 3 per 1000 in 1987 to 59 per 1000 in 1997, 73\% of the cases being in the third and fourth decades of life, i.e., the most productive years. The male to female ratio was $3.1: 1$ and $29 \%$ of the patients had the full-blown disease. A total of $80.5 \%$ acquired the infection heterosexually. And only $2 \%$ of the patients were intravenous drug users. The percentage of patients acquiring infection through blood, blood products, and hemodialysis dropped from $20 \%$ in 1987 to $5 \%$ in 1997, but the cumulative figure was still $12 \%$. The infections showed an upward trend till 2005 although national survey of southern states showed a marginal decline [8]. Finally, with revamping of the entire blood banking system and universal screening of blood and blood products after a Supreme Court judgment following public interest litigation [9], the blood born infections fell rapidly to less than $1 \%$.

\section{Spread of HIV from High Risk to Low Risk Groups}

Truck drivers were detected to be a major high risk group .In a study conducted in Punjab in 1993. Of the 232, 3 were positive (17 per thousand) [10]. Only 12 visited specific red light areas while the rest regularly indulged in promiscuous behavior with strangers in primitive enclosures or open air make shift brothels shielded by bushes adjoining the food kiosks. Most of the sex workers were married house wives and entertained 4 - 6 customers during the day for 1 US dollar per customer. Thus the epidemic spread from high risk truck drivers to low risk 


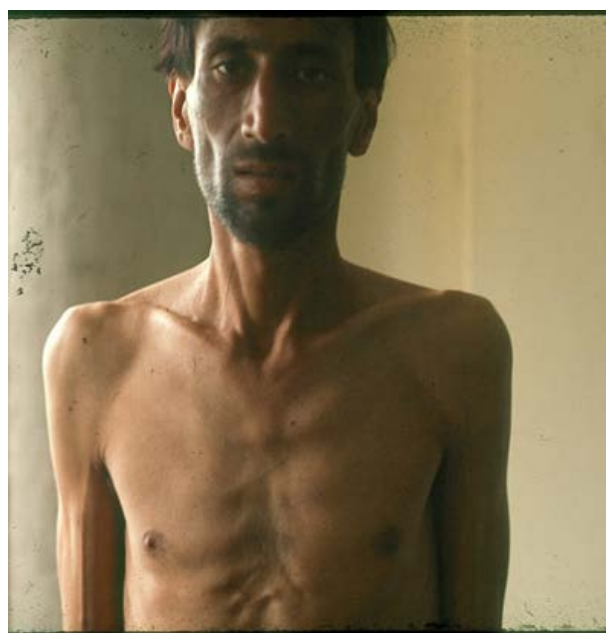

(a)

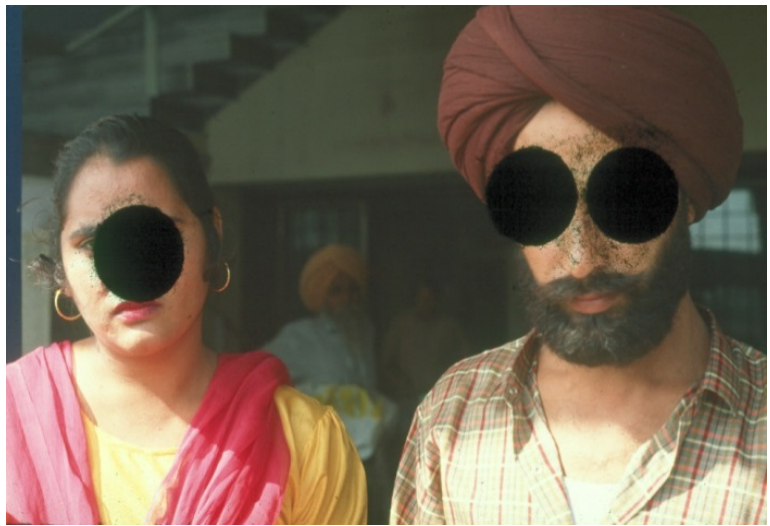

(b)

Figure 4. (a) Shows a driver from USA who came with wasting, florid pneumocystis carinii infection and died soon after. (b) Shows his widow on the left and younger brother of the patient who were staying as husband and wife with consent of the family after a "chaddar" ceremony. Before we could counsel, husband's younger brother was already HIV positive.

house wives. None of them ever used a condom at that time. History of a genital ulcer was obtained in $57.7 \%$ of drivers. None of them knew that healthy person could transmit the disease. This gross ignorance in the initial phase of the epidemic caused a rapid spread across the country via the highways. A strategic plan was introduced by NACO to curtail the spread along the highways during NACP2 [11]

\section{HIV Spread in India}

The disease spread through road and rail from high risk coastal areas of Maharashtra and Tamil Nadu where long distance truck drivers indulged in high risk behavior along the high ways. The prevalence of HIV increased rapidly in other states of Gujarat, Andhra and Karnataka. The coastal areas of India although bore the major brunt Bombay (Mumbai) appeared to be the AIDS capital of India, At the end of the 1980s; however; a rapid spread of HIV was also observed among injecting drug users (IDUs) in Manipur, Mizoram and Nagaland [12], the three north-eastern states of India bordering Myanmar (Burma). By 1990 cases of HIV infection had been reported in every state of the country although the pattern differed in different states, HIV had spread to the general population [13].

The North eastern state of Assam had shown a quantum jump in the number of cases. In 2001 the number of people living with AIDS was 364 which increased to 4231 in 2009. The neighboring state of Manipur had 1070 patients. North east borders the heroin producing Golden Triangle of Laos, Myanmar and Thailand and also has high rates of IV drug users. Secondly, many armed insurgent groups are active in this region with poor infrastructure. In Bodoland, Assam, there are relief camps of internationally displaced persons nearly (200,000) without proper food .They are promised jobs as domestic help in big cities. This fuelling traffic facilitated the spread of HIV in the neighboring states (Nedan foundation) [14]. Narzary noted that young women had gone missing from the camps and analysts feared that the "missing girls" might have been sold into sexual slavery or "temporarily married”. Reports indicate that hordes of North East "women continued to be put for sale as bonded laborers, as wives to men too old or infirm and as prostitutes around the country". Such a situation was likely to fuel the spread in spite of efforts of NACO. The Norwegian Refugee Council (NRC) estimated that up to 200,000 people were displaced in 2003 in Assam state alone and a further 15,000 in neighboring Tripura state. In the 2004 clashes, 70 people died and 30,000 displaced [15].

\section{Preventive Strategies}

In 1986 an AIDS Task Force was set up under the Indian Council of medical research. Subsequently, National AIDS Control Programme was launched with the help of World Bank to co-ordinate national responses. Its ac- 
tivities covered surveillance, blood screening, and health education. By the end of 1987, out of 52,907 subjects tested, around 135 people were found to be HIV positive and 14 had AIDS. Most of these initial cases had occurred through heterosexual route [16].

In 1992 the government set up NACO (the National AIDS Control Organization), to oversee the formulation of policies, prevention work and control programmes relating to HIV and AIDS. In the same year, the government launched a Strategic Plan, the National AIDS Control Programme (NACP) for HIV prevention. This plan established the administrative and technical basis for programme management and also set up State AIDS Control Societies (SACS) in 25 states and 7 union territories. The following is the time line of activities [17].

NACP 1-1992-1997-99 included mass program for information education and communication, safety of blood products following litigation filed by an NGO, propagating condom usage, monitor trends and offer some elementary treatment facilities

NACP 2-1999-2007 (international support including GATES foundation): set up for targeted intervention strategies for high risk groups. In 2001, the government adopted the National AIDS Prevention and Control Policy and former Prime Minister Atal Bihari Vajpayee referred to HIV/AIDS as one of the most serious health challenges facing the country when he addressed parliament [18]. Vajpayee also met the chief ministers of the six high-prevalence states to plan the implementation of strategies for HIV/AIDS prevention. The number of licensed blood banks increased to 1230 including 82 component separating centers. Voluntary counseling and testing centers were set up; investigating mother to child transmission, offering free antiretroviral therapy to antenatal mothers was started only in April 2004.

NACP 3-2007-2012. The third phase (NACP III) began in 2007, with the highest priority placed on reaching 80 percent of high-risk groups including sex workers, men who have sex with men, and injecting drug users with targeted interventions with the help of community organizations in partnership with the State AIDS Control Societies. The achievements of NACO in bringing down new infections have been lauded by the International agencies.

\section{Evolving Epidemiological Scenario}

In 2006 UNAIDS estimated that there were 5.6 million people living with HIV in India, which indicated that there were more people with HIV in India than in any other country in the world [19]. In 2007, however, following the first survey of HIV among the general population, UNAIDS and NACO agreed on between 2 million and 3.1 million people living with HIV [20]. In 2008 and 2009 it was estimated to be 2.3 and 2.4 million respectively. As per UNDP's 2010 report, India had 2.39 million (23.95 lakh) people living with HIV at the end of 2009, up from 2.27 million (22.7 lakh) in 2008. Adult prevalence also rose from $0.29 \%$ in 2008 to $0.31 \%$ in 2009 [21]. In a recent press release by the health minister of India, a drastic drop in new infections up to 57\% has been reported in India [22]. Thus containment of AIDS epidemic in India has indeed been a success story.

The prevalence varied greatly in different states. Andhra Pradesh had the highest burden of HIV infection. The HIV prevalence at antenatal clinics was $1 \%$ in 2007 while HIV prevalence at STD clinics and MSM stood at $17 \%$ each, female sex workers at $9.7 \%$.HIV prevalence among injecting drug users was $16.8 \%$, third highest out of all reporting states (Tables 1 and 2). In Karnataka, districts with high prevalence tend to be located in and around Bangalore or in northern Karnataka's “devadasi belt”. Devadasi women regularly indulged in sanctioned

Table 1. State wisedistribution of prevalence rates in high risk groups (year 2007 estimates: NACO report).

\begin{tabular}{|c|c|c|c|c|c|}
\hline States (population) In lacs & Antenatal clinic. & STD & IDU & MSM & Sex worker \\
\hline Andhra (76) & 1.00 & 17.20 & 3.71 & 17.04 & 9.74 \\
\hline Manipur (2.4) & 0.75 & 4.08 & 17.90 & 16.40 & 13.07 \\
\hline Mizoram (1) & 0.75 & 7.13 & 7.53 & --- & 7.20 \\
\hline Karnataka (53) & 0.50 & 8.40 & 2.00 & $\underline{17.60}$ & 5.30 \\
\hline Maharashtra (97) & 0.50 & 11.62 & 24.40 & 11.80 & 17.91 \\
\hline Tamilnadu (66) & 0.25 & 8.00 & 16.80 & 6.60 & 4.68 \\
\hline Chandigarh (12) & 0.25 & 0.42 & 8.64 & 3.60 & 0.40 \\
\hline
\end{tabular}


Table 2. Current estimates in some of the high positivity areas: (NACP 3: states fact sheet March 2012).

\begin{tabular}{ccccc}
\hline States & Positivity & PLHA & New infections & Deaths \\
\hline Manipur & 1.40 & 26,733 & 1219 & 1700 \\
Andhra & 0.90 & 499,620 & 23,905 & 35,694 \\
Mizoram & 0.81 & 6025 & 409 & 362 \\
Nagaland & 0.78 & 13,120 & 704 & 783 \\
Karnataka & 0.63 & 245,522 & 9184 & 9356 \\
Gujarat & 0.37 & 136,874 & 4283 & 1635 \\
Maharashtra & 0.33 & 154,741 & & 12459 \\
Tamil Nadu & 0.33 & 154,742 & 850 & 85 \\
Chandigarh & 0.39 & 3067 & 217 & 3989 \\
Punjab & 0.32 & 56927 & 1970 & 1772 \\
Delhi & 0.30 & 34,216 & 7316 & 14154 \\
West Bengal & 0.29 & 167,994 & & 3989 \\
\hline
\end{tabular}

prostitution and this part of the country was responsible for sex trade in big cities such as Mumbai [23].

\section{Drug Users in Punjab}

Although IV drug users typically segregated in the North East in the beginning, a subsequent study conducted by NACO, however, revealed a sharp increase in the prevalence of IV drug users increased sharply in Punjab to 13.8\% in 2007 [24]. Ludhiana, one of the richest cities in the Punjab, with 21\%, Amritsar, reached a disturbing $30 \%$ [25]. Broun, head of UNAIDS in India has stated, "the problem of IDUs has been underestimated in mainland India, as most of the problem was thought to be in the northeast" [26].

The Indian Government and NACO helped to establish hundreds of integrated counseling and testing centers (ICTCs) in India. By the end of 2009 there were 5135 ICTCs in India, [27] compared to just 62 in 1997 [28]. By 2009, these centers had tested 13.4 million people for HIV, an increase from 4 million in 2006 [29].

\section{Predominant Type of Virus Prevalent in North India}

A genetic analysis of HIV-1 from Punjab, India, though revealed the presence of multiple variants, seven HIV isolates from Punjab, India were closely linked to South African NOF strain [30]. On distance and parsimony trees, most of the Indian sequences clustered together as subtype C. However, sequences from three patients also showed significant homologies and phylogenetic clustering outside of subtype C.

A study was conducted employing a simple ELISA assay on 100 HIV positive sera collected at PGIMER using different synthetic peptides from the $\mathrm{V}$ loop to ascertain the type of virus prevalent in India. Peptides were prepared from MN, NOF, EL1, 111B and Indian strain; i.e. peptides of North American, African, European and of Indian origin respectively [31]. Results indicated that $82 \%$ of the patients harbored a strain related to the NOF or South African strain. The first complete nef sequence of primary HIV1 isolate from North India was published in 1998 [32] which further substantiated its homology to subtype C. Full length sequence was published by Lole et al. from Mumbai [33]. This observation was quite puzzling at that time as we had not detected any case coming from South Africa but from other parts of Africa.

Link to South Africa: an hypothesis: Several reports reveal that drug trafficking from Mumbai, Gujarat, Srilanka to South Africa via the sea route was rampant in eighties and nineties. Huge quantities of mandrax (methaqualone) costing 20 billion rupees were estimated to be smuggled to South Africa; the biggest user of mandrax at that time. Many drug houses in India shifted to mandrax production from paracetamol (acetaminophen) manufacturing units which were more profitable [34]-[36]. It is possible that on return route the HIV virus was brought back to the coastal areas of India. This might explain the intriguing relationship between predominant Indian isolates and South African isolates. 
Pediatric HIV and AIDS: Gaitonde Centre for AIDS Research and Education (YRG CARE) in Chennai has had long experience of caring for HIV-positive children. Currently around 380 children are under care at YRG CARE, close to 100 of whom are receiving antiretroviral (ARV) treatment [37]. The clinical profile of 516 children affected by HIV was evaluated at the Advanced Pediatric Center, PGIMER Chandigarh, India, during the period January 1994 to May 2008 [38]. A total of 454 children (327 boys and 127 girls) infected by HIV were analyzed with a median age at presentation of 54 months. Of these children, $88.3 \%$ acquired the infection vertically and 5.7\% through transfusion of blood/blood products. Common clinical features included fever (36.6\%), respiratory infections (31.7\%), lymphadenopathy (30.0\%), hepatosplenomegaly (21.8\%) and diarrhea (18.1\%); and $65.9 \%$ were malnourished. Triple drug antiretroviral therapy was initiated in 205 children who showed significant improvement and follow-up rates improved markedly following free supply of the drug. Merchant $e t a l$. from Mumbai have given an excellent account of clinical features of pediatric AIDS from Mumbai [39].

\section{Confections in Adult Patients}

Predominant clinical symptoms in these patients were weight loss, fever, diarrhea, cough, candidiasis, weakness etc. Patients also had pleural effusion, hilar lymphadenopathy.

During the early epidemic, tuberculosis was present in nearly $46 \%$ of AIDS patients. Co infections with CMV in these patients were studied using primers from immediate early genes of the CMV genome. Of the 37 patients with AIDS, 12 (32.4\%) showed a positive reaction by PCR and 4 patients were positive by the antigenemia assay. Similarly active EBV infection was common in AIDS patients [40]-[42]. Kaposi sarcoma, however, is almost unknown in Indian patients with AIDS.

\section{Cellular and Serological Markers of Disease Activity in Indian Patients with HIV/AIDS}

There had been an exponential rise of HIV positive patients as observed at the surveillance center of Nehru Hospital. Most patients were poor and could not afford repeated viral load assays. Therefore, there is a need to identify cost effective and reliable surrogate markers of disease activity. In one study [43] several parameters were studied in 30 patients of AIDS and an equal number of seropositives and healthy controls.

The mean CD4 cells in patients with AIDS were $69.66 \pm 68.25 \mathrm{~mm}^{3}$ while in seropositives, the value was 370 $\pm 201.29 \mathrm{~mm}^{3}$. The mean CD4 cells in healthy controls were however $690 \pm 198 \mathrm{~mm}^{3}$. The differences in all the groups were highly significant $(\mathrm{p}<0.001)$. The mean CD4 values in Indians are significantly lower than reported from the west. The CD8 cell number in controls was $650 \pm 207 \mathrm{~mm}^{3}$ this high figure could be due to immune activation in Indian population. P-24 assay and beta 2 microglobulin levels failed to delineate clearly between seropositives and patients with AIDS. The correlation between CD4 cells and viral load was more significant when the CD4 cells were below $200 \mathrm{~mm}^{3}$. Five out of 30 patients with a CD4 of $300-600 \mathrm{~mm}^{3}$ had a viral load of over $1 \times 10^{5} \mathrm{cop} / \mathrm{ml}$. The difference in TNF R-II levels between seropositives and AIDS was however more impressive. With a cutoff of $550 \mathrm{pg} / \mathrm{ml}$ it had a sensitivity of $95 \%$ in delineating HIV from AIDS. It was concluded that a combination of absolute number of CD4 cells and TNF R-II assay along with clinical evaluation could be used to monitor therapy in resource poor countries where frequent viral load assays or CD4 cell numbers are unaffordable.

\section{Poor Response to Vaccine}

In a study conducted by Pasricha et al. [44], a suboptimal response to HBV was observed in patients with a CD 4 count of less than $200 / \mathrm{mm}^{3}$.

\section{Cell Susceptibility of Clade C Virus}

The Role of clade C envelope V3 to V5 region on viral entry, co-receptor utilization and replication efficiency in primary T lymphocytes was studied by Sundaravardan et al. [45]. They documented that sub type V3 - V5 region chimeras of Indian clade C and clade B failed to replicate in T lymphocyte cell lines but replicated in peripheral blood mononuclear cells (PBMC) and monocyte derived macrophages (MDM) and utilized CCR5 co receptors rather than CXCR 4.The authors showed that subtype C contributes to higher HIV replication com- 
pared to sub type B isolates. These subtype C chimeras were unable to induce syncytia in MT-2 cells, indicative of non-syncytium inducing (NSI) phenotypes. Taken together, these results suggest that the envelope V3 to V5 regions of subtype $\mathrm{C}$ contributed to higher levels of HIV-1 replication compared with subtype B chimeras, which may contribute to higher viral loads and faster disease progression in subtype $\mathrm{C}$ infected individuals than other subtypes as well as rapid HIV-1 subtype C spread in India.

\section{Opt-Out Screening for HIV in a Tertiary Care Hospital}

A preliminary opt-out screening study for HIV was conducted at PGIMER according to Center for Disease Control (CDC) guidelines. A total of 876 cases were screened for HIV during August 2010 to December 2010. The prevalence of HIV in emergency and pre-surgical setting was 21 per thousand. Positivity rate in the pediatric population was 20.9 per thousand while in adults it was 21.4 per thousand [46]. Most patients were totally unsuspected. Nearly 40,000 patients seek admission annually to the emergency department of PGIMER. Thus nearly 700 to 800 patients may be missed every year if one does not resort to such a practice. Since India still has a large number of HIV cases, opt-out screening program and testing in an emergency setting, as recommended by CDC, are extremely relevant especially when cure is possible with early intervention [47]. There is no role for complacence as indicated by a recent surge of HIV deaths in the state of Amritsar, Punjab. Several new groups e.g. men having sex with men (MSM) and IV drug users have emerged in different states and would continue to pose fresh challenges.

\section{References}

[1] Bureau of Hygiene \& Tropical Diseases (1986) AIDS Newsletter.

[2] Ghosh, T.K. (1986) AIDS: A Serious Challenge to Public Health. Journal of the Indian, 1, 29-30.

[3] Simoes, A.F., Babu, G., John, T.J. Nirmala, S. and Solomon, S. (1987) Evidence for HTLV-III Infection in Prostitutes in Tamil Nadu (India). Indian Journal of Medical Research, 85, 335-338.

[4] Sehgal, S., Arora, S.K, Rajwanshi, A and Deodhar, S.D. (1988) AIDS in India. II. Asian Pacific Journal of Allergy and Immunology, 6, 39-42.

[5] Sehgal, S. (1992) Comparative evaluation of HIV infected foreign students and Indian with AIDS in Chandigarh, India. Asian Pacific Journal of Allergy and Immunology, 10, 141-143.

[6] Sehgal, S. (1995) HIV Epidemic in Punjab. Indian Journal of Medical Research, 101, 47-49.

[7] Sehgal, S. (1998) Time Trends of HIV Epidemic in Punjab: A Decade of Observation. Bulletin of the World Health Organization, 76, 509-513.

[8] Prasada Rao, J.V.R., Ganguly, N.K., Mehendale, S.M. and Bollinger, R. (2004) India’s Response to HIV Epidemic. The Lancet, 364, 9442-9444.

[9] Krishnan, J. (2003) The Rights of the New Untouchables: A Constitutional Analysis of HIV Jurisprudence in India. Human Rights Quarterly, 25, 791-781.

[10] Singh, B., Bedi, Y.P., Singh, S. and Sehgal, S. (1994) AIDS Awareness among Truck Drivers in Punjab. Annals of the National Academy of Medical Sciences (India), 30, 129-132.

[11] NACO (2005) UNGASS India Report: Progress Report on the Declaration of Commitment on HIV/AIDS’ITCT.

[12] Pal, S.C., Sarkar, S., Naik, T.N., Singh, P.K., Toshi, S.I., Shiv, L. and Tripathy, S.P. (1990) Explosive Increase of HIV Infection in North East States of India; Manipur and Nagaland. Bulletin of the Center for AIDS Research and Control, 3, 2-6.

[13] History of the HIV Epidemic and the Country’s Response. http://www.avert.org/aidsindia.htm

[14] www//nedan.in. nedan_trafnaids_north_east 070402 (2006) Trafficking and HIV/AIDS, North East Report.

[15] Www//Norwegian Refugee Council (2013) Advocacy > Climate Change > Global Estimatesや. Internal Displacement Group.

[16] Kakar, D.N. and Kakar, S.N. (2001) Combating AIDS in the 21st century Issues and Challenges. Sterling Publishers Private Limited, 32.

[17] Prasanna, K. (2013) The National AIDS Control Programme (1, 2, 3)/Response.infochangeindia.org/hiv-aids.

[18] HIV/AIDS September (2001) AtalBihari Vajpayee, Speech at the Meeting with Chief Ministers of High Prevalence States on the Issue of Control and Prevention of HIV/AIDS, New Delhi. 
[19] www/UNAIDS.org/knowledgecenter (2006) Report on the Global AIDS Epidemic.

[20] UNAIDS (2007) Press Release: 2.5 Million People in India Living with HIV According to New Estimates.

[21] UNAIDS (2010) UNAIDS Report on the Global AIDS Epidemic.

[22] HIV Estimations (2012) Report Released. Press Information Bureau, Government of India Ministry of Health and Family Welfare, 40.

[23] Sivaram S. (2002) Integrating Income Generation and AIDS Prevention Efforts: Lessons from Working with Devadasi Women in Rural Karnataka, India.

[24] NACO (2008) Annual Report NACO 2008-09.

[25] UNGASS (2010) India-Country Progress Report.

[26] UNODC (2007) Feature-Drug Users Raise Risk of HIV in India's heartland.

[27] UNGASS (2010) India-Country Progress Report.

[28] NACO (2005) UNGASS India Report: Progress Report on the Declaration of Commitment on HIV/AIDS.

[29] WHO/UNAIDS/UNICEF (2011) Global HIV/AIDS Response: Epidemic Update and Health Sector Progress towards Universal Access 2011.

[30] Jameel, S., Zafarullah, M., Ahmed, M., Kapoor, G.S. and Sehgal, S. (1995) A Genetic Analysis of HIV-1 from Punjab, India Reveals the Presence of Multiple Variants. AIDS, 9, 685-690.

http://dx.doi.org/10.1097/00002030-199507000-00003

[31] Sehgal, S., Pasricha, N. and Jameel, S. (1996) Serotype Analysis of Indian Patients with HIV Infection. Tropical Medicine \& International Health, 1, 199-204.

[32] Ahmed, K.M., Mujtaba, S., Das, R., Zafrullah, M., Sehgal, S. and Jameel, S. (1998) NeF Sequence of Primary HIV 1. Isolate from North India. Human Retrovirus \& AIDS Research, 14, 1491-1493. http://dx.doi.org/10.1089/aid.1998.14.1491

[33] Lole, K., Bollinger, R.C., Paranjape, R.C., Gadkari, D., Kulkarni, S.S., Novak, N.G., et al. (1999) Full-Length Human Immunodeficiency Virus Type 1 Genomes from Subtype C-Infected Seroconverters in India, with Evidence of Inter-subtype Recombination. Journal of Virology, 73, 152-160.

[34] Chakrabarti Sumon, K. (2008) CNN IBN: Dawood turns Mandrax King Updated Apr 17, at 02:56 am IST.

[35] Animesh, R. (2006) Briefing India an Emerging Hub of International Drug Trafficking. Society for the Study of Peace and Conflict at New Delhi.

[36] (2008) Office of Drug and Crime Report (ODC Report) from South Africa. 25-20.

[37] Solomon, S. (2003) YRG CARE. Integrated Preventive Care and Support Services, Horizon and International HIV/AIDS Alliance.

[38] Singh, S., Jat, K.R., Suri, D., Arora, S.K., Minz, R. and Sehgal, S. (2009) Clinical Profile of 516 Children Overview of HIV and AIDS in India. Retrieved from Affected by HIV in a Tertiary Care Center in Northern India: 14 Years of Experience. Transactions of the Royal Society of Tropical Medicine and Hygiene, 103, 627-633. http://dx.doi.org/10.1016/j.trstmh.2009.01.009

[39] Merchant, R.H. and Lala, M.M. (2011) Principles of Perinatal and Pediatric HIV/AIDS. JP Brothers, New Delhi.

[40] Sehgal, S., Varma, S., Rajwanshi, A., Sood, A., Dash, R.J., Singh, K., et al. (1997) Incidence of Tuberculosis in AIDS Patients in Punjab: A Retrospective Study. In: Aggarwal, O.P., Sharmam, A.K. and Indrayan, A., Eds., HIV \& AIDS Research in India, NACO, Ministry of Health, New Delhi, 602-604.

[41] Sud, A., Sehgal, S., Sharma, M., Varma, S., Kumar, B. and Varma, S. (2000) Spectrum of Secondary Infections Associated with HIV Infection in North India. Annals of the National Academy of Medical Sciences (India), 35, 151-158.

[42] Mujtaba, S., Varma, S. and Sehgal, S. (2003) Cytomegalovirus Co-Infection in Patients with HIV/AIDS in North India. Indian Journal of Medical Research, 117, 99-103.

[43] Sehgal, S., Mujtaba, S., Sud, A., Datta, U. and Vinayak, V.K. (2002) Cellular and Serological Markers of Disease Activity in Indian Patients with HIV/AIDS. Methods in Cell Science, 24, 107-114.

[44] Pasricha, N., Datta, U., Chawla, Y., Singh, S., Arora, S.K., Sud, A., Minz, R.W., Saikia, B., Singh, H., James, I. and Sehgal, S. (2006) Immune Responses in Patients with HIV Infection after Vaccination with Recombinant Hepatitis B Virus Vaccine. BMC Infectious Diseases, 6, 65.

[45] Sundaravaradan, V., Das, S.R., Ramakrishnan, R., Sehgal, S., Gopalan, S., Ahmad, N. and Jameel, S. (2007) Role of HIV-1 Subtype C Envelope V3 to V5 Regions in Viral Entry, Co-Receptor Utilization and Replication Efficiency in Primary T-Lymphocytes and Monocyte-Derived Macrophages. Virology Journal, 4, 126.

http://dx.doi.org/10.1186/1743-422X-4-126 
[46] Minz, R.W., Singh, S., Varma, S., Mathuria, S.N., Aggrawal, R. and Sehgal, S. (2010) Relevance of Opt-Out Screening for HIV in Emergency and Pre-Surgery Patients in a Tertiary Care Center in Northern India: A Pilot Study. Indian Journal of Pathology \& Microbiology, 53, 287-289. http://dx.doi.org/10.4103/0377-4929.64334

[47] Jefferys, R. and McEnery, R. (2013) A Toddler Stole the Show: Report of a Child Functionally Cured of HIV Stirred Up the Typically Staid Proceedings of the Conference on Retroviruses and Opportunistic Infections. IAVI Report, 17, 4-8. 